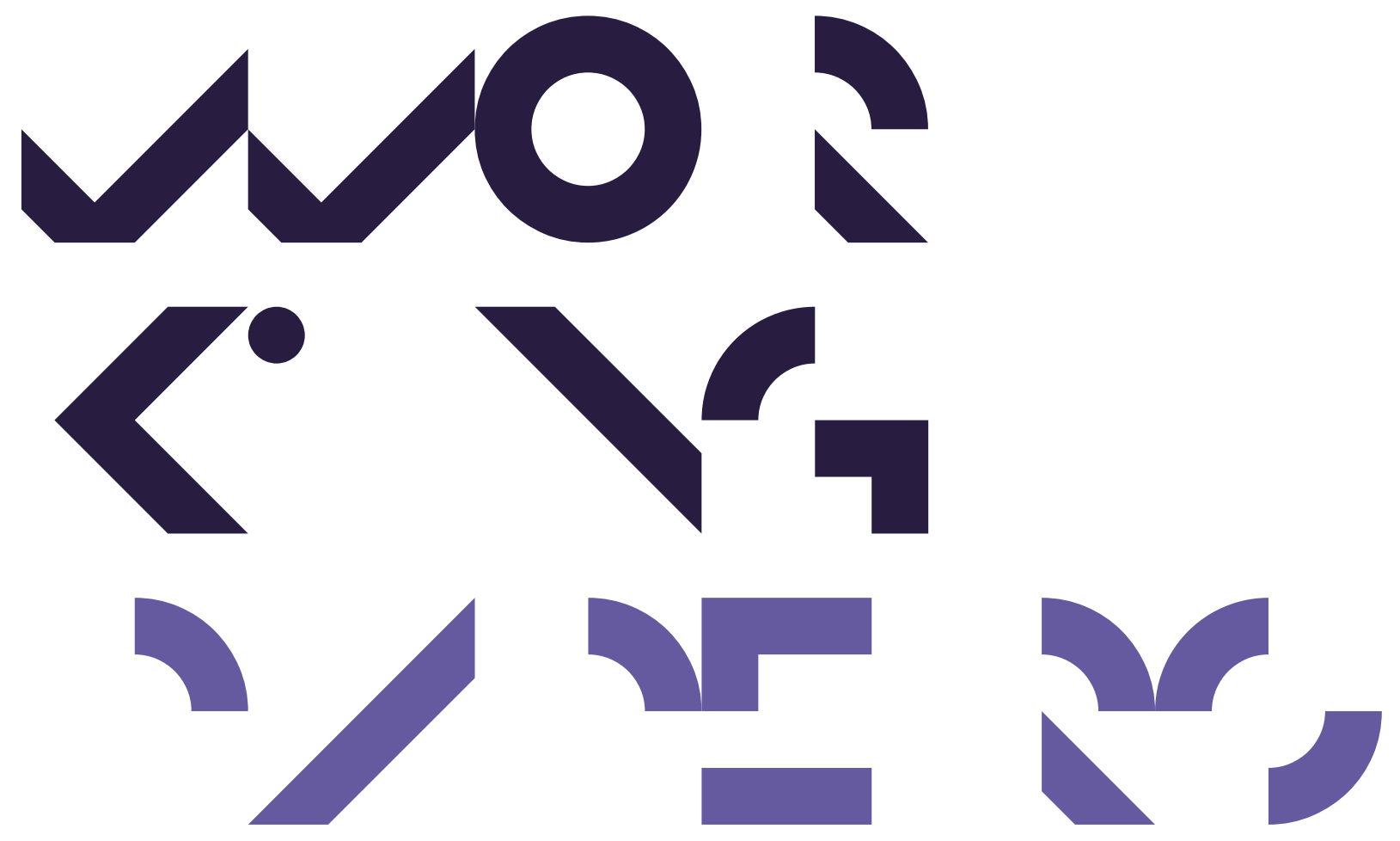

Economics Working Papers

2015-24

Extensive Margins of Offshoring and Exporting

Anders Rosenstand Laugesen 


\title{
Extensive Margins of Offshoring and Exporting
}

\author{
Anders Rosenstand Laugesen*
}

December 15, 2015

\begin{abstract}
This paper derives new comparative statics within a two-country version of the recent offshoring model by Antràs, Fort, and Tintelnot (2014) with nonprohibitive costs of exporting final goods. One key finding is that an asymmetric trade liberalisation might very well imply that the fractions of offshorers and exporters increase in one country and decrease in the other country. This model outcome occurs when competition enhances in a country experiencing a decline in its costs of international trade. The fractions of offshorers and exporters certainly increase in a small open economy experiencing a decline in its costs of international trade. These strong industry-level results appear even though the comparative statics at the firm level are nonmonotone and asymmetric across the heterogeneous firms.
\end{abstract}

Keywords: Firm Heterogeneity; Offshoring; Exporting; Trade Liberalisation

JEL Classifications: D21; F12; F61; L23

*Aarhus University, Denmark. Email: arl@econ.au.dk. This project has benefited from useful comments at the 2015 CESifo workshop "New Developments in Global Sourcing". 


\section{Introduction}

Over the past decade, the literature on heterogeneous firms in international trade has understandably paid a lot of attention to the exporting decision. Key studies in this respect are, to mention just a few, Melitz (2003), Helpman et al. (2004), Chaney (2008), Melitz and Ottaviano (2008), Arkolakis (2010), and Eaton et al. (2011). Another influential strand of the heterogeneous-firms literature has accentuated decisions on importing of intermediate goods, i.e. offshoring. One reason for this might be that this particular kind of international trade has risen over the past couple of decades and now comprises a substantial part of international trade as documented by, for instance, Hummels et al. (2001), Yi (2003), and Johnson and Noguera (2012). Some influential studies in this strand of literature are Antràs and Helpman (2004), Goldberg et al. (2010), Amiti and Davis (2012), and Kasahara and Lapham (2013). Interestingly enough, the latter two studies reveal that the decisions to export final goods and to offshore production of intermediate inputs interact and can be complementary to each other. Moreover, the studies by Bas (2012), Bas and Strauss-Kahn (2014), and Albornoz and Lembergman (2015) provide tentative empirical evidence for this particular complementarity which points to the importance of attempting to encompass both exporting and offshoring within an integrated model. ${ }^{1}$

This paper contributes by deriving novel comparative statics within an integrated model of international trade where monopolistically competitive heterogeneous firms decide upon their extensive margin offshoring and exporting strategies. This integrated model has recently been proposed by Antràs et al. (2014) (henceforth AFT) and is taken at face value. In a natural extension of their baseline offshoring model to nonprohibitive costs of trading final goods across countries, AFT briefly analyse the problem of heterogeneous firms determining their extensive margin offshoring and exporting decisions in a world consisting of multiple countries. This extension, which is treated in their Section 3.5, forms the basis of the present analysis. In contrast to AFT, we mainly confine ourselves to just two asymmetrical countries as this strengthens our results.

Importantly, the extensive margin offshoring and exporting decisions are complementary to each other under a particular parameterisation which re-

\footnotetext{
${ }^{1}$ Across U.S. manufacturing industries, the correlation between the fraction of exporters and the fraction of offshoring firms is 0.87 and significant (Bernard et al., 2012).
} 
ceives empirical support in AFT. This paper reveals that this complementarity at the firm level has a clear-cut impact at the industry level under an asymmetric trade liberalisation. An asymmetric trade liberalisation implies that the fractions of offshorers and exporters increase in the country directly benefiting from the liberalisation while these fractions simultaneously decrease in the other country if the level of competition enhances in the directly benefiting country. The industry-level implications for the two countries are thus precisely opposite. Whether or not competition actually enhances in a given country can be checked through counterfactual simulations as done by AFT. We also show that the result above generalises to the case where firms are heterogeneous not only with respect to productivity but also with respect to the fixed costs of global sourcing. With or without multidimensional firm heterogeneity, the level of competition certainly enhances in a country directly benefiting from the asymmetric trade liberalisation when this country can be characterised as a small open economy. This implies that the fractions of offshorers and exporters certainly increase in a small open economy directly benefiting from the asymmetric trade liberalisation. Finally, it should be mentioned that these strong industry-level results hold even though the comparative statics at the firm level are shown to be nonmonotone and asymmetric across the heterogeneous firms.

The results mentioned above are interesting since the analytical comparative statics in AFT treat the levels of competition in the various countries as exogenous during comparative statics based on trade liberalisations. This is not particularly appealing under monopolistic competition where free entry is a key characteristic of the long-run equilibrium. General equilibrium comparative statics in AFT are based on counterfactual simulation exercises. This paper shows how analytical results can be obtained when one allows for endogenous levels of competition and free entry. These results aim at strengthening the intuition behind the complex AFT model in which only relatively few comparative statics have been derived so far. The analysis below draws upon the mathematics of complementarity and the monotonicity theorem of Topkis (1978) in particular. For this reason, most technical details are relegated to Appendix A. Moreover, this paper heavily relies on the methodology developed by Laugesen (2015) and can quite simply be perceived as an application of that method of deriving comparative statics to the AFT model. 


\section{Model}

AFT have recently developed a quantifiable multi-country model of global sourcing in which monopolistically competitive heterogeneous firms decide upon their offshoring and, potentially also, their exporting strategies. Offshoring occurs when intermediate inputs are produced abroad. The gains from offshoring in the AFT model consist of a variable cost reduction which comes at the cost of higher fixed costs. The pros and cons of exporting are exactly similar to those in Melitz (2003): exporting of final goods opens the door to additional markets and sales also at the cost of higher fixed costs. The basic model structure in AFT draws intensively on Melitz (2003). The present paper, which presents some novel comparative statics based upon the AFT model, lets the cost of exporting final goods be nonprohibitive implying that some firms export their final goods in equilibrium. This is done in order to bridge the two different literatures on offshoring and exporting.

Using Section 3.5 of AFT and the underlying appendix, we can express the problem of an actively producing firm from the home country (country 1 ) with productivity $\theta$ determining its extensive margin offshoring and exporting strategies as

$$
\begin{aligned}
\max _{I_{12}^{M} \in\{0,1\}, I_{12}^{X} \in\{0,1\}} & \left(\gamma \sum_{j=1}^{2} I_{1 j}^{M} T_{j}\left(\tau_{1 j} w_{j}\right)^{-\psi}\right)^{(\sigma-1) / \psi} \sum_{k=1}^{2} I_{1 k}^{X}\left(\tau_{1 k}^{X}\right)^{1-\sigma} A_{k} \theta \\
& -w_{1} \sum_{j=1}^{2} I_{1 j}^{M} f_{1 j}-w_{1} \sum_{k=1}^{2} I_{1 k}^{X} f_{1 k}^{X},
\end{aligned}
$$

where the notation is now explained. Keep in mind that the model is explained from the view point of country 1 . The choice variables, $I_{12}^{M}$ and $I_{12}^{X}$, are zero-one indicator functions for offshoring the production of intermediates $(M)$ and exporting final goods $(X)$ to country 2, respectively. For the present purpose, $\gamma>0$ can be perceived as a parameter even though $\gamma$ is in fact a function of several parameters that are kept constant during the comparative statics. $j \in\{1,2\}$ and $k \in\{1,2\}$ are country indices.

Following most of the heterogeneous-firms trade literature, we restrict attention to equilibria where trade cost parameters are such that the least productive active firms do neither export final goods nor offshore production of intermediates. This is in line with the empirical findings in, for instance, Kohler and Smolka (2011), Bernard et al. (2012), Antràs and 
Yeaple (2014), and AFT. All assumptions throughout also apply to the foreign country (country 2). The sorting assumption above implies that $\bar{x} \equiv\left(I_{11}^{M}, I_{12}^{M}, I_{11}^{X}, I_{12}^{X}\right)=(1,0,1,0)$ for the least productive active firms in the home country (country 1 ) where $I_{11}^{M}$ and $I_{11}^{X}$ are indicator functions for procuring intermediates and selling final goods in the home country, respectively. Analogously, the least productive active firms in the foreign country (country 2) choose $\bar{x}_{f} \equiv\left(I_{22}^{M}, I_{21}^{M}, I_{22}^{X}, I_{21}^{X}\right)=(1,0,1,0)$ where $I_{2 j}^{M}$ and $I_{2 k}^{X}$ are foreign firm indicator functions for procuring intermediates and selling final goods in country $j$ and $k$, respectively.

$T_{j}>0$ denotes the country $j$ technology level relevant for the production of intermediates. $\tau_{1 j}$ and $\tau_{1 k}^{X}$ denote the iceberg trade costs of, respectively, procuring intermediates in country $j$ and selling final goods in country $k$ from the view point of country 1 firms. $w_{j}$ denotes the (constant) labour wage rate in country $j$ which is determined through an assumption of free trade in an outside good produced under perfect competition and constant returns to scale. $\psi$ is a positive parameter. $\sigma>1$ denotes the constant elasticity of substitution between final-good varieties originating from the assumed CES preference structure. Let us henceforth assume that $(\sigma-1)>\psi$ such that the extensive margin offshoring and exporting decisions are complementary as in e.g. Amiti and Davis (2012). The results of the empirical analysis in AFT are in line with this key assumption which, by the complementarities of the model and the monotonicity theorem of Topkis (1978), implies that $I_{11}^{M}=I_{11}^{X}=1$ for all active firms in the home country. Similarly, $I_{22}^{M}=I_{22}^{X}=1$ for all active firms in the foreign country. This is because the vectors, $\bar{x}$ and $\bar{x}_{f}$, are nondecreasing in productivity as shown in $\mathrm{AFT}^{2}{ }^{2} f_{1 j}$ denotes the positive fixed cost of procuring intermediate inputs from country $j . f_{1 k}^{X}$ denotes the positive fixed cost of selling final goods in country $k$. $A_{k}$ can be interpreted as an endogenous inverse measure of the level of competition in the monopolistically competitive industry in country $k$ and will be referred to as the demand level in country $k$. As shown in AFT, $A_{k}$ is an increasing function of the CES price index in country $k$.

Notice that in contrast to AFT who allow for $J$ asymmetric countries, we will mainly constrain ourselves to just two asymmetric countries, namely the home country 1 and the foreign country 2. This choice is made since the results are stronger in this case when we allow for nonprohibitive costs of

\footnotetext{
${ }^{2}$ Note that the profit function in (1) is supermodular in $\bar{x}$ and exhibits increasing differences in $(\bar{x}, \theta)$.
} 
exporting. ${ }^{3}$ Let $\beta=\left(-\tau_{12},-\tau_{12}^{X},-f_{12},-f_{12}^{X}\right)$ be the vector of parameters that we weakly increase during the comparative statics where all other parameters (including the trade costs relevant for country 2) are held constant for reasons of tractability. Hence, $\beta$ contains minus the fixed and minus the variable costs of trading final goods and intermediate inputs across countries from the view point of country 1 firms. An increase in $\beta$ amounts to an asymmetric trade liberalisation where increases in $-\tau_{12}$ and $-f_{12}$ can be perceived as input-trade liberalisations by country 1 . Increases in $-\tau_{12}^{X}$ and $-f_{12}^{X}$ can be perceived as final-good import trade liberalisations by country 2 . For these reasons, an increase in $\beta$ will be denoted an asymmetric and not an unilateral trade liberalisation.

Assume an equilibrium with free entry which determines the two demand levels, $A_{1}$ and $A_{2}$, as functions of $\beta$ and other parameters. Firms realise their productivity, $\theta$, upon paying an entry cost but before making their extensive margin offshoring and exporting decisions. Finally, assume that firms with sufficiently low productivity draws decide not to become active since active production would imply negative profits in (1). Such an equilibrium appears when $f_{11}, f_{11}^{X}, f_{22}$, and $f_{22}^{X}$ are sufficiently large. Notice that nonactive firms choose $\bar{x}=(0,0,0,0)$ and $\bar{x}_{f}=(0,0,0,0)$ in the home and foreign countries, respectively, as nonactive firms do neither sell final goods nor procure intermediates. Consequently, the optimal choices of $\bar{x}$ and $\bar{x}_{f}$ govern both the decision of whether or not to become active as well as the extensive margin offshoring and exporting decisions. This goes to show that we have two alternative ways of expressing the AFT model above. On the one hand, we can let firms face the problem (1) with $I_{11}^{M}=I_{11}^{X}=1$ implying that firms leave the industry when the value function (1) assumes negative values. On the other hand, we can let firms maximise the same supermodular profit function by varying $\bar{x}$ and detect whether a firm is active or not by checking the optimal values of $I_{11}^{M}$ and $I_{11}^{X}$. This completes the description of the model. The next section presents a series of results that hold for the version of the AFT model presented above. Rest assured that all results will be proved in Appendix A.

\footnotetext{
${ }^{3}$ Comparative statics for the AFT model with $J$ potentially asymmetric countries can easily be derived using the approach of Bache and Laugesen (2014) given that firms do not export their final products. Allowing for exporting complicates the analysis because exporting firms are exposed to different endogenous demand levels, $A_{k}$.
} 


\section{$2.1 \quad$ Results}

Under the set of assumptions made in Section 2, an asymmetric trade liberalisation through an increase in $\beta$ implies that the fractions of offshorers and exporters increase in country 1 if productivity is distributed Pareto while $A_{1}$ is nonincreasing as a consequence of the increase in $\beta$. This required adjustment in $A_{1}$ amounts to an increase in competition in country 1. Moreover, when $A_{1}$ is nonincreasing and productivity is also distributed Pareto in country 2 , the fractions of offshorers and exporters simultaneously decrease in country 2 as a consequence of the increase in $\beta$. Hence, the complementarity between offshoring and exporting at the firm level has a clear impact at the industry level under the asymmetric trade shock.

These sharp industry-level results for the two countries also hold when the total fixed cost function in (1) is increasing in the extensive margin offshoring and exporting decisions and submodular in these decisions instead of additively separable and thus modular. This is because the complementarity between offshoring and exporting in (1) is preserved under this alternative assumption. Notice that a submodular total fixed cost function allows for the a priori plausible case where the fixed cost of exporting to a country is lower if a firm already has some useful knowledge about this particular country through its offshoring experience in this country (and vice versa). The evidence in Kasahara and Lapham (2013) is consistent with such cost complementarities. See also the recent work by Albornoz and Lembergman (2015) which argues that exporting to a given destination reduces the fixed cost of offshoring to that particular destination.

As a small digression, let us mention that qualitatively similar industrylevel comparative statics for country 1 can be found within a multi-country AFT model with $J$ asymmetric countries, nonprohibitive costs of exporting, and Pareto-distributed productivities if the induced changes (by an increase in $\beta$ ) in all foreign demand levels, $A_{2}$ to $A_{J}$, are nonnegative while the induced change in $A_{1}$ is nonpositive. This is for instance the case when country 1 is a small open economy. The intuition is provided in the next paragraph.

It can be shown that an increase in $\beta$ certainly implies increasing fractions of offshorers and exporters in country 1 if this country can be characterised as a small open economy with positive production of differentiated final goods and Pareto-distributed productivities, $\theta$. This is because $A_{1}$ is certainly nonincreasing in this case since $A_{2}$ (up to $A_{J}$ in a $J$-country model) is unaffected by the shock to the small open economy named country 1 . The nonincrease 
in $A_{1}$ follows from the fact that all country 1 firms make weakly higher profits as a consequence of the increase in $\beta$ at given demand levels, $A_{1}$ and $A_{2}$. Since $A_{2}$ is constant when country 1 is a small open economy, and since profits are strictly increasing in $A_{1}, A_{1}$ must decrease in order to satisfy the free-entry condition in country 1 .

Recall that the complementarities of the model imply that the vectors, $\bar{x}$ and $\bar{x}_{f}$, are both nondecreasing in productivity. It follows that at most three out of four possible combinations of extensive margin offshoring and exporting decisions are seen in a given equilibrium of a two-country model. This is somewhat unattractive given the diversity in business strategies often seen in empirical studies like Tomiura (2007) and Kohler and Smolka (2011). In addition to this, the empirical analysis in AFT points in the direction of firm-specific idiosyncrasies in the choices of strategy. For all these reasons, we now follow Section 5 in AFT by introducing firm-country-specific fixed costs of global sourcing. Hence, we now let the fixed costs of procuring intermediates, $f_{1 j}$ and $f_{2 j}$, be firm-country-specific and given by $f_{1 j}^{n}>0$ and $f_{2 j}^{n}>0$ where $n$ is a firm identifier and $j \in\{1,2\}$. Let us also follow AFT in assuming that the distributions of $f_{1 j}^{n}$ and $f_{2 j}^{n}$ across firms are independent of the distributions of productivity which are assumed to be Pareto in both countries. Under these assumptions, it follows that an increase in $\tilde{\beta} \equiv\left(-\tau_{12},-\tau_{12}^{X},-f_{12}^{X}\right)$ implies that the fractions of offshorers and exporters increase in country 1 if $A_{1}$ is nonincreasing. Moreover, the fractions of offshorers and exporters simultaneously decrease in country 2 as a consequence of the increase in $\tilde{\beta}$ if the induced change in $A_{1}$ is nonpositive. Under this generalisation, an increase in $\tilde{\beta}$ certainly implies increasing fractions of offshorers and exporters in country 1 if this country can be characterised as a small open economy with positive production of differentiated final goods.

While the above results make it clear that the comparative statics might very well be monotone at the industry level of analysis, things are much less clear at the firm level under the standard assumption of free entry in the two countries. In this case, the comparative statics at the firm level are nonmonotone, asymmetric across firms, and entirely in line with the simulated results in Section 6.1 of AFT which allows for general-equilibrium effects. However, our results at the firm level are not in line with the analytical firm-level comparative statics in AFT as these latter comparative statics hold the demand levels constant for simplicity. This is clearly at odds with free entry as acknowledged by AFT. We discuss these findings and discrepancies in more detail in Appendix A. To sum up, the monotone industry-level results do not 
arise based on an aggregation of monotone firm-level results. This is because these sharp industry-level results also depend upon the masses of exiting and entering firms in the home and foreign countries, respectively. The sizes of these masses in turn depend upon the distributions of firm productivity.

In absence of good theoretical guidance from the literature, the needed nonincrease in $A_{1}$ can easily be checked for provided that one has access to a dataset like for instance the one used by AFT. See for instance the counterfactual simulation exercise in Section 6.1 in AFT which confirms the needed demand-level adjustment (a nonincrease in $A_{1}$ ) under an increase in $-\tau_{12}$ in a $J$-country model with prohibitive costs of exporting. Similar counterfactual simulation exercises can also be applied to the present context with nonprohibitive costs of exporting. Appendix A will show analytically that increases in $-\tau_{12}$ always lead to a nonincrease in $A_{1}$ in a $J$-country model with prohibitive costs of exporting. However, more theoretical work is clearly needed in order to figure how asymmetric liberalisations of both input and output trade affect the levels of competition in the asymmetric countries. This task is left to future research. As previously mentioned, all the above claims are proved in Appendix A.

\section{Conclusion}

This paper has shown how to obtain analytical comparative statics within the quantifiable multi-country model of global sourcing recently proposed by AFT. One main ambition of the present study has been to strengthen the intuition behind some key mechanisms and results within the complex AFT model. For simplicity, the analytical comparative statics in AFT treat the various demand levels as constants implying that at least one free-entry condition is violated. Under constant demand levels, AFT show that the firmlevel comparative statics are monotone. General equilibrium comparative statics in AFT are based on counterfactual simulation exercises. This paper has shown that the allowance for a free-entry equilibrium renders the firmlevel comparative statics nonmonotone and asymmetric across firms as also seen in the counterfactual simulations in AFT. Despite these nonmonotone firm-level results, the comparative statics at the industry level might very well be monotone because of induced changes in the sets of active firms. The industry-level comparative statics are certainly monotone in the case of a small open economy experiencing a decline in its costs of international trade. 


\section{A Appendix}

Let us start by ignoring the possibility of multidimensional firm heterogeneity. Section 2.1 claimed that an increase in $\beta$ implies that the fractions of offshorers and exporters increase in country 1 while these fractions simultaneously decrease in country 2 if productivity is distributed Pareto in both countries and the induced change in $A_{1}$ is nonpositive. The task of proving this main result is relatively easy since the AFT model in Section 2 is nested within the slightly more general model in Laugesen (2015). In fact, the claim above follows readily from Propositions 1 and 2 in that paper. We proceed by showing how Propositions 1 and 2 in the paper by Laugesen can be applied to the present context. To do this, we emphasise important assumptions of the AFT model in Section 2. Once it is clear to the reader that the assumptions and sufficient conditions in Laugesen (2015) also hold in the present context, it will also become clear that the claims above are true.

First, we analyse firm behaviour conditional on active production and make a series of observations which illustrate the similarity between the AFT model above and Laugesen (2015). Let us focus on domestic (country 1) firms but let it be mentioned that similar observations hold for country 2 firms. Profits in (1) are strictly increasing and continuous in $\theta$ and the domestic demand level, $A_{1}$. Firm profits are weakly increasing in the foreign demand level, $A_{2}$, and strictly increasing for firms selling final goods abroad. All active firms face a decision about $x=\left(I_{12}^{M}, I_{12}^{X}\right)$ subject to the constraint that $x \in S \subseteq X=\{0,1\} \times\{0,1\}$ where $X$ is a lattice and $S$ is a sublattice. The exposition focuses on the case where $X$ and $S$ are always equal to each other. Under Pareto-distributed productivities, $\theta$, some firms serve the consumers abroad since productivities are unbounded from above and trade costs are finite. ${ }^{4}$ Note that $A_{1}, A_{2}$, and $\theta$ only enter the profit function through the products, $A_{1} \theta$ and $A_{2} \theta$, implying that profits in the problem (1) can be written as $\pi=\pi\left(x ; A_{1} \theta, A_{2} \theta, \beta\right)$. Importantly, $\pi\left(x ; A_{1} \theta, A_{2} \theta, \beta\right)$ in (1) is supermodular in $x$ and exhibits increasing differences in $\left(x, A_{1} \theta\right),\left(x, A_{2} \theta\right)$, and $(x, \beta) .{ }^{5}$ By assumption, the least productive active firms do not engage in international trade. It follows that the key Assumptions 1 to 3 in Laugesen (2015) are satisfied. Note that the profit function in (1) is additively separable

\footnotetext{
${ }^{4}$ Using the original notation of AFT, $\theta$ in Section 2 equals $\varphi^{\sigma-1}$ in AFT. Recall that $\theta$ is distributed Pareto when $\varphi$ is distributed Pareto.

${ }^{5}$ Recall that profits are supermodular in $\bar{x}$. As $\left(I_{11}^{M}, I_{11}^{X}\right)=(1,1)$ is optimally chosen in (1), it follows by Theorem 4.3 in Topkis (1978) that supermodularity in $x$ is preserved.
} 
in the products, $A_{1} \theta$ and $A_{2} \theta$.

Let us define a productivity threshold for active production,

$\theta_{a}\left(A_{1}\right) \equiv \inf \left\{\theta: \pi^{*}\left(A_{1} \theta, A_{2} \theta, \beta\right)>0\right\}=\inf \left\{\theta: \bar{x}^{*}\left(A_{1} \theta, A_{2} \theta, \beta\right) \geq(1,0,1,0)\right\}$

where $\pi^{*}$ denotes optimal firm profits, (1), and $\bar{x}^{*}$ denotes the optimal choice of the extended decision vector, $\bar{x}$. In Section 2's version of the AFT model, we have that

$$
\theta_{a}\left(A_{1}\right)=\frac{w_{1}\left(f_{11}+f_{11}^{X}\right)}{\left(\gamma T_{1}\left(\tau_{11} w_{1}\right)^{-\psi}\right)^{(\sigma-1) / \psi}\left(\tau_{11}^{X}\right)^{1-\sigma} A_{1}},
$$

where $\theta_{a}\left(A_{1}\right)$ is, importantly, neither directly affected by $A_{2}$ nor by $\beta$. Recall that the lowest productivity firms are assumed not to be able to produce profitably.

By the monotonicity theorem of Topkis (1978), the optimal $x$, $x^{*}\left(A_{1} \theta, A_{2} \theta, \beta\right)$, is nondecreasing in $\left(A_{1} \theta, A_{2} \theta, \beta\right)$. Next, define

$$
\theta_{i}\left(x_{i} ; A_{1}, A_{2}, \beta\right) \equiv \max \left\{\theta_{a}, \inf \left\{\theta: x_{i}^{*}\left(A_{1} \theta, A_{2} \theta, \beta\right) \geq x_{i}\right\}\right\}
$$

where $x_{i}^{*}$ denotes the optimal level of activity (choice variable) $i \in\{1,2\}$ and where $x_{i} \in\{0,1\}$ denotes a particular level of activity $i$. We will henceforth let activity 1 be offshoring and let activity 2 be exporting. Hence, $\theta_{i}\left(x_{i} ; A_{1}, A_{2}, \beta\right)$ is the lowest level of productivity at which a country 1 firm undertakes at least level $x_{i} \in\{0,1\}$ of activity $i \in\{1,2\}$. It is important to realise that $\theta_{1}\left(1 ; A_{1}, A_{2}, \beta\right)$ and $\theta_{2}\left(1 ; A_{1}, A_{2}, \beta\right)$ denote the productivity thresholds for offshoring and exporting, respectively, in country 1 . Furthermore, $\theta_{1}\left(0 ; A_{1}, A_{2}, \beta\right)=\theta_{2}\left(0 ; A_{1}, A_{2}, \beta\right)=\theta_{a}\left(A_{1}\right)$ as we constrain ourselves to equilibria where the least productive active firms do neither export final goods nor offshore production of intermediates.

Laugesen (2015) imposes the key Assumption 4 saying that the percentage increase in $\theta_{a}$ induced by a decline in $A_{1}$ weakly exceeds the percentage increase in $\theta_{i}$ induced by a decline in $A_{1}$. It is important to realise that this assumption holds in Section 2. This is verified by checking the productivity thresholds for exporting and offshoring when these are functions of demandlevel variables like the threshold for active production, (2). Since $x^{*}$ is nondecreasing in $\theta$, as argued above, the exporting threshold, $\theta_{2}\left(1 ; A_{1}, A_{2}, \beta\right)$, takes one of three different forms depending on parameter values. The exporting threshold may either lie above or below the offshoring threshold, 
$\theta_{1}\left(1 ; A_{1}, A_{2}, \beta\right)$, and it may also coincide with the offshoring threshold productivity level. In all three cases, it is simple to show that the percentage increase in $\theta_{a}$ induced by a decline in $A_{1}$ weakly exceeds the percentage increase in the exporting threshold. The same can be said about the offshoring threshold which might either lie below, lie above, or coincide with the exporting threshold productivity depending on parameter values. Hence, Assumption 4 in Laugesen (2015) holds in Section 2.

Let $F(\theta)$ denote the distribution of productivities. Notice that $s_{a} \equiv$ $1-F\left(\theta_{a}\right)$ denotes the share of active firms and $s_{i} \equiv 1-F\left(\theta_{i}\right) \leq s_{a}$ denotes the share of firms undertaking at least level $x_{i}$ of activity $i$. The equilibrium distribution function for activity $i$ across active firms is thus expressed as

$$
H_{i}\left(x_{i} ; \beta\right) \equiv 1-\frac{s_{i}\left(x_{i} ; A_{1}, A_{2}, \beta\right)}{s_{a}\left(A_{1}\right)} .
$$

Finally, we are equipped to show that an increase in $\beta$ implies that the fractions of offshorers and exporters increase in country 1 while these fractions simultaneously decrease in country 2 if productivity is distributed Pareto in both countries and the induced change in $A_{1}$ is nonpositive. This is done by arguing that, in country 1 , an increase in $\beta$ induces nondecreases in $1-H_{1}(1 ; \beta)=\frac{s_{1}\left(1 ; A_{1}, A_{2}, \beta\right)}{s_{a}\left(A_{1}\right)}$ and $1-H_{2}(1 ; \beta)=\frac{s_{2}\left(1 ; A_{1}, A_{2}, \beta\right)}{s_{a}\left(A_{1}\right)}$ if productivity is distributed Pareto and the induced change in $A_{1}$ is nonpositive, while, in country 2, the exact opposite result holds for the activities $I_{21}^{M}$ and $I_{21}^{X}$ under the same two conditions. Given that the exposition in Section 2 squares perfectly with the methodology and assumptions in Laugesen (2015) as illustrated above, this main industry-level comparative static follows from Propositions 1 and 2 in Laugesen (2015). ${ }^{6}$ As it is clear from Appendix A in Laugesen (2015), the mentioned monotone industry-level results do not arise based on an aggregation of monotone firm-level results. In fact, the comparative static effects of an increase in $\beta$ at the firm level are nonmonotone under a decrease in $A_{1}$. More on this later.

Next, it was claimed that these sharp industry-level results for the two countries generalise to the case where the total fixed cost function in (1) is increasing in the extensive margin offshoring and exporting decisions and submodular in these decisions instead of additively separable. This is true

\footnotetext{
${ }^{6}$ Note that the total direct effect, the total domestic indirect effect, and the total foreign indirect effect mentioned by Laugesen (2015) are all nonpositive in country 1 and all nonnegative in country 2 .
} 
since $\pi\left(x ; A_{1} \theta, A_{2} \theta, \beta\right)$ remains supermodular in $x$ and still exhibits increasing differences in $\left(x, A_{1} \theta\right),\left(x, A_{2} \theta\right)$, and $(x, \beta)$ in this alternative case. These properties are part of the sufficient conditions in Laugesen (2015).

After an increase in $\beta$, increasing fractions of offshorers and exporters in country 1 can also be found within a multi-country setup including $J$ asymmetric countries and nonprohibitive costs of exporting if the induced changes in all foreign demand levels, $A_{2}$ to $A_{J}$, are nonnegative while the induced change in $A_{1}$ is nonpositive. This follows from a straightforward generalisation of the decomposition (7) in Laugesen (2015) to $J-1$ total foreign indirect effects which are all nonpositive. The total domestic indirect effect remains nonpositive like the total direct effect when $A_{1}$ is nonincreasing and productivity is distributed Pareto because it remains true that the percentage increase in $\theta_{a}$ induced by a decline in $A_{1}$ weakly exceeds the percentage increase in $\theta_{i}$ (for all $2(J-1)$ activities) induced by a decline in $A_{1}$. This is because the $J$-country generalisation of (1) is additively separable in $A_{1} \theta, A_{2} \theta, \ldots, A_{J} \theta$.

It was mentioned that an increase in $\beta$ certainly implies increasing fractions of offshorers and exporters in country 1 if this country can be characterised as a small open economy with positive production of differentiated goods and Pareto-distributed productivities, $\theta$. This follows from Proposition 1 and Corrollary 1 in Laugesen (2015) since $A_{1}$ is certainly nonincreasing in this case, as explained in Section 2.1, while $A_{2}$, by assumption, is unaffected by the increase in $\beta$.

Now, consider the case where the fixed costs of procuring intermediates, $f_{1 j}$ and $f_{2 j}$, are firm-country-specific and given by $f_{1 j}^{n}$ and $f_{2 j}^{n}$ where $n$ is a firm identifier. The distributions of these fixed costs across firms are independent of the Pareto distributions of productivities in both countries. The number of countries, $J$, again equals two. In Section 2.1, it was claimed that an increase in $\tilde{\beta}=\left(-\tau_{12},-\tau_{12}^{X},-f_{12}^{X}\right)$ implies that the fractions of offshorers and exporters increase in country 1 and decrease in country 2 if $A_{1}$ is nonincreasing. Notice that the profit function in (1) can now be written as $\pi\left(x ; A_{1} \theta, A_{2} \theta, \tilde{\beta}\right)$. This function is supermodular in $x$ and exhibits increasing differences in $\left(x, A_{1} \theta\right),\left(x, A_{2} \theta\right)$, and $(x, \tilde{\beta})$. Recall that the least productive active firms do not engage in international trade. Importantly, Assumptions 1 to 4 in Laugesen (2015) also hold under this extension to multidimensional firm heterogeneity. Under these observations, the correctness of the claimed result follows readily from Proposition 4 in Laugesen (2015). Also under this generalisation, an increase in $\tilde{\beta}$ certainly implies increasing fractions of 
offshorers and exporters in country 1 if this country can be characterised as a small open economy with positive production of differentiated final goods. This is true because the total foreign indirect effect and the total domestic indirect effect in Laugesen (2015) are, respectively, zero and nonpositive since $A_{2}$ is constant and $A_{1}$ certainly nonincreases. ${ }^{7}$

As previously mentioned, the comparative static effects of an increase in $\beta$ at the firm level are nonmonotone and asymmetric. It was also claimed that the comparative statics at the firm level are in line with the simulation results in Section 6.1 of AFT. In their conclusion, AFT write: "A distinctive characteristic of our framework is that a sectoral import competition shock that does not simultaneously increase export opportunities may still lead to intraindustry reallocation effects by which firms sourcing from these shocked countries may expand, while those not sourcing from those countries shrink". This finding follows from the counterfactual simulation exercise within a $J$ country model with prohibitive costs of exporting in Section 6.1 of AFT. This exercise also reveals that an increase in $-\tau_{12}$ induces a nonincrease in $A_{1}$. First, this latter finding can also be shown analytically. To see this, note that profits of country 1 firms do not depend on foreign demand levels in the AFT model with prohibitive costs of exporting, cf. (1). At a given $A_{1}$, an increase in $-\tau_{12}$ implies that all country 1 firms make higher profits as also argued by AFT on page 14. Hence, in order to satisfy the free-entry condition in country $1, A_{1}$ must decrease as also found by AFT in their simulation exercise. Second, this drop in $A_{1}$ in turn implies that firms not sourcing from country 2 shrink as also seen in Section 6.1 AFT. This is because these firms are only affected by the adverse general equilibrium effect through the decrease in $A_{1}$. Third, in addition to this adverse general equilibrium effect, more productive firms (or firms with lower $f_{12}^{n}$ ), which source from country 2 , are also directly affected by the increase in $-\tau_{12}$. These firms may thus expand as also emphasised in the quote by AFT.

Finally, it was claimed that our firm-level results are not in line with the analytical firm-level comparative statics in Section 3.5 of AFT as these latter comparative statics hold the demand levels constant. As argued in several instances, this assumption is at odds with free entry. On page 19, AFT write: "For instance, holding constant the vector of residual demand parameters $B_{i}$ [which equals $A_{i}$ in the present paper], reductions in the costs of

${ }^{7}$ The intuition for this nonincrease in $A_{1}$ is the same as in the case without multidimensional firm heterogeneity and was explained in Section 2.1. 
trading final goods across countries will not only increase the participation of firms in export markets, but will also increase the extensive margin of global sourcing." This result critically hinges upon the constant demand levels. To see this, take the case where the number of countries in Section 3.5 of AFT is 2 and let us for simplicity abstract from multidimensional firm heterogeneity. First, note that an increase in $\left(-\tau_{12}^{X},-f_{12}^{X}\right)$ implies that $A_{1}$ and $A_{2}$ must both move and in opposite directions. This follows from the two freeentry conditions. ${ }^{8}$ In general, we do unfortunately not know what demand level variable increases and what decreases. ${ }^{9}$ Note that an increase in the extensive margin of global sourcing for all firms occurs when the productivity threshold for offshoring decreases. However, this productivity threshold will not decrease when the model parameters are such that the productivity threshold for offshoring lies below the productivity threshold for exporting and $A_{1}$ nonincreases. ${ }^{10}$ Consequently, the comparative statics are certainly at odds with the results of AFT when country 1 can be described as a small open economy. In the reverse case, $A_{1}$ increases wherefore $A_{2}$ decreases when country 1 is not a small open economy. This may imply that the productivity threshold for exporting increases such that the extensive margin of exporting decreases for some firms. ${ }^{11}$ To sum up, we have found that allowing for free entry renders the comparative statics at the firm level nonmonotone.

\section{References}

Albornoz, F., Lembergman, E.G., 2015. Importing after Exporting. Working Paper.

Amiti, M., Davis, D.R., 2012. Trade, Firms, and Wages: Theory and Evidence. Review of Economic Studies 79, 1-36.

\footnotetext{
${ }^{8}$ By the free-entry condition in country $1, A_{1}$ and $A_{2}$ must adjust. By the free-entry condition in country 2 , the directions of change in $A_{1}$ and $A_{2}$ differ. From this free-entry condition we also see that a strict increase in one demand level variable implies a strict decrease in the other since some firms export.

${ }^{9}$ This is why our main industry-level comparative statics are conditional on a nonincrease in $A_{1}$.

${ }^{10} \theta_{1}\left(1 ; A_{1}, A_{2}, \beta\right)=\frac{w_{1} f_{12}}{\left[\left(\gamma\left(T_{1}\left(\tau_{11} w_{1}\right)^{-\psi}+T_{2}\left(\tau_{12} w_{2}\right)^{-\psi}\right)\right)^{(\sigma-1) / \psi}-\left(\gamma T_{1}\left(\tau_{11} w_{1}\right)^{-\psi}\right)^{(\sigma-1) / \psi}\right]\left(\tau_{11}^{X}\right)^{1-\sigma} A_{1}}$ when $\theta_{1}\left(1 ; A_{1}, A_{2}, \beta\right)<\theta_{2}\left(1 ; A_{1}, A_{2}, \beta\right)$.

${ }^{11} \theta_{2}\left(1 ; A_{1}, A_{2}, \beta\right)=\frac{w_{1} f_{12}^{X}}{\left(\gamma T_{1}\left(\tau_{11} w_{1}\right)^{-\psi}\right)^{(\sigma-1) / \psi}\left(\tau_{12}^{X}\right)^{1-\sigma} A_{2}} \quad$ when $\quad \theta_{1}\left(1 ; A_{1}, A_{2}, \beta\right) \quad>$ $\theta_{2}\left(1 ; A_{1}, A_{2}, \beta\right)$.
} 
Antràs, P., Helpman, E., 2004. Global Sourcing. Journal of Political Economy $112(3), 552-580$.

Antràs, P., Yeaple, S.R., 2014. Multinational Firms and the Structure of International Trade, in: Handbook of International Economics. Elsevier.

Antràs, P., Fort, T.C., Tintelnot, F., 2014. The Margins of Global Sourcing: Theory and Evidence from U.S. Firms. Working Paper.

Arkolakis, C., 2010. Market Penetration Costs and the New Consumers Margin in International Trade. Journal of Political Economy 118(6), 11511199.

Bache, P.A., Laugesen, A., 2014. Monotone Comparative Statics for the Industry Composition. Working Paper.

Bas, M., 2012. Input-Trade Liberalisation and Firm Export Decisions: Evidence from Argentina. Journal of Development Economics 97, 481-493.

Bas, M., Strauss-Kahn, V., 2014. Does Importing more Inputs raise Exports? Firm-Level Evidence from France. Review of World Economics 150, 241275.

Bernard, A.B., Jensen, J.B., Redding, S.J., Schott, P.K., 2012. The Empirics of Firm Heterogeneity and International Trade. Annual Review of Economics 4, 283-313.

Chaney, T., 2008. Distorted Gravity: The Intensive and Extensive Margins of International Trade. The American Economic Review 98, 1707-1721.

Eaton, J., Kortum, S., Kramarz, F., 2011. An Anatomy of International Trade: Evidence from French Firms. Econometrica 79(5), 1453-1498.

Goldberg, P.K., Khandelwal, A.K., Pavcnik, N., Topalova, P., 2010. Imported Intermediate Inputs and Domestic Product Growth: Evidence from India. The Quarterly Journal of Economics 125(4), 1727-1767.

Helpman, E., Melitz, M.J., Yeaple, S.R., 2004. Export Versus FDI with Heterogeneous Firms. American Economic Review 94(1), 300-316. 
Hummels, D., Ishii, J., Yi, K.M., 2001. The Nature and Growth of Vertical Specialization in World Trade. Journal of International Economics 54, 75-96.

Johnson, R.C., Noguera, G., 2012. Fragmentation and Trade in Value Added over Four Decades. Working Paper.

Kasahara, H., Lapham, B., 2013. Productivity and the Decision to Import and Export: Theory and Evidence. Journal of International Economics 89(2), 297-316.

Kohler, W., Smolka, M., 2011. Sourcing Premia with Incomplete Contracts: Theory and Evidence. The B.E. Journal of Economic Analysis \& Policy $11(1), 1-39$.

Laugesen, A.R., 2015. Asymmetric Monotone Comparative Statics for the Industry Compositions. Working Paper.

Melitz, M.J., 2003. The Impact of Trade on Intra-Industry Reallocations and Aggregate Industry Productivity. Econometrica 71(6), 1695-1725.

Melitz, M.J., Ottaviano, G.I.P., 2008. Market Size, Trade, and Productivity. Review of Economic Studies 75, 295-316.

Tomiura, E., 2007. Foreign Outsourcing, Exporting, and FDI: A Productivity Comparison at the Firm Level. Journal of International Economics 72(1), 113-127.

Topkis, D.M., 1978. Minimizing a Supermodular Function on a Lattice. Operations Research 26, 305-321.

Yi, K.M., 2003. Can Vertical Specialization Explain the Growth of World Trade? Journal of Political Economy 111(1), 52-102. 


\section{Economics Working Papers}

2015-10: $\quad$ Peter S. Eppinger, Nicole Meythaler, Marc-Manuel Sindlinger and Marcel Smolka: The Great Trade Collapse and the Spanish Export Miracle: Firm-level Evidence from the Crisis

2015-11: Ella Paldam and Martin Paldam: The political economy of churches in Denmark over 700 years

2015-12: Ina C. Jäkel and Marcel Smolka: Trade Policy Preferences and the Factor Content of Trade

2015-13: Rene Saran and Norovsambuu Tumennasan: Implementation by Sortition in Nonexclusive Information Economies:

2015-14: Torben M. Andersen: The Greenlandic Economy - Structure and Prospects

2015-15: Jos Jansen: A Note on Quality Disclosure and Competition

2015-16: Martin Paldam: The rational economist in research: A model

2015-17: Kenneth Lykke Sørensen: Heterogeneous Impacts on Earnings from an Early Effort in Labor Market Programs

2015-18: $\quad$ Leonie Gerhards and Christina Gravert: Grit Trumps Talent? An experimental approach

2015-19: Ritwik Banerjee: On the indterpretation of World Values Survey trust question - global expectations vs. local beliefs

2015-20: $\quad$ Karl Fritjof Krassel and Kenneth Lykke Sørensen: Childhood and Adulthood Skill Acquisition - Importance for Labor Market Outcomes

2015-21: Erik Strøjer Madsen and Simon Hartington: Disruptive technologies and networking in telecom industries

2015-22: $\quad$ Anders Rosenstand Laugesen: Asymmetric Monotone Comparative Statics for the Industry Compositions

2015-23: John Kennes, Daniel Monte and Norovsambuu Tumennasan: Dynamic Matching Markets and the Deferred Acceptance Mechanism

2015-24: Anders Rosenstand Laugesen: Extensive Margins of Offshoring and Exporting 